\title{
Internal Communication Issues in the Firms: Does It Affect the Productivity?
}

\author{
Luz Angela Martinez Martinez ${ }^{1} \&$ Saul Rick Fernandez Hurtado ${ }^{2}$ \\ ${ }^{1}$ Professional in Industrial Engineering, Department of operations and System, Universidad Autónoma de Occidente, \\ Cali, Colombia \\ ${ }^{2}$ Postdoctor Globalization and Regional Development, Center for Global Studies, Shanghai University, Shanghai, China. \\ $\mathrm{PhD}$ Management Science and Engineering, Center for innovation and Knowledge Management, Shanghai University, \\ Shanghai, China. Professor and Researcher, Universidad Santiago de Cali, Cali, Colombia; Research Seminar \\ Coordinator "The Challenge of Research - tCR"; Principal Project Researcher "Estudio de viabilidad para la creación \\ del centro estratégico de desarrollo del pacifico colombiano - CEDEPA", Universidad Santiago de Cali, Cali, \\ Colombia.
}

Correspondence: Luz Angela Martinez Martinez, Avenida 6 Norte No. 40-30 Apar. 101 Barrio la Flora, Edificio el Naranjal, Cali - Colombia. E-mail: luz_angela.martinez@uao.edu.co, saulrick@163.com

\author{
Received: June 14, 2017 Accepted: January 8, 2018 Online Published: February 12, 2018 \\ doi:10.5539/res.v10n2p1 URL: https://doi.org/10.5539/res.v10n2p1
}

\begin{abstract}
Communication is born as a response of the human being to interact with other people in companies to motivate human resource and obtain the expected results and work with the best workers in an increasingly competitive market; internal communication plays an important role in improving the working environment and an excellent performance of workers. The constant change brought about by world globalization, forces organizations to apply methods that organize the means to lead the company to obtain better performance and make full use of all its resources; without it, it is created an environment of instability and uncertainty among its members. Business communication can be seen as a strategic tool in relation to the organization with the environment and interaction with the staff, showing the results expected by the company analyses by empirical data. The research is developed through a descriptive and empirical methodology to identify through surveys to workers from different companies, the current problems presented by organizations in internal communication; thus establishing the consequences of poor organizational communication; finding the real problems that affect the companies of the Colombian industry and of the world, to find possible solutions.
\end{abstract}

Keywords: internal communication, companies, competitiveness, human resource, labor climate

\section{Introduction}

In the 18th century and at the beginning of the 19th century, transcendental changes took place in Europe that affected the rest of the world, the civil warriors, the French revolution and the industrial revolution, since they brought new changes to humanity. The industrial revolution generated impacts and fundamental changes in the economy, technology and in the way of organizing work and the lifestyle of the population. Improving processes in firms was gaining more importance when they were parameterizing the principles of work organization; the parameters start with capitalism and the boom of industry, emerging paradigms in aspects of work such as productivity, competitiveness, and efficiency.

Due to the processes and changes that were gradually caused by globalization, a new need arises in companies to adapt and apply new methodologies within the company in order to structure communication channels to improve quality in the processes and products, leading the company to be more competitive in the environment and obtain better performance, making full use of all its resources.

Proposes the bases of relations in the business environment, as the industry examines how to satisfy communication needs, benefiting the company and achieving customer satisfaction, reaching a synergy between workers and company goals (Casillas \& Moreno-Menéndez, 2017).

When the great crises appeared in countries like United States of America, England, Germany that left thousands of people unemployed, an atmosphere of distrust on the part of the workers was generated, because of this the public relations are born, when the great depression happens in the United States of America, this is where employers decide to rely on workers and recognize that the solution to the problem of productivity was to maintain constant feedback with 
employees. Workers were no longer seen as a factor of production to be considered as proactive, efficient, innovative, which is motivated by a series of factors in the environment; emerging skills competencies and the ability to influence people to achieve the objectives of the organization, through management indicators, measure the effectiveness of communication and the productive projection of each company; transmitting values to progress in a sustainable manner.

\section{Problem Statement}

Internal communication in organizations is one of the fundamental axes to face each of the challenges related to market expansion, globalization, quality, and competitiveness. Faced with these business challenges, organizations must not only be focused on the economy, production, and administration but also communication as the main axis of business action; because this constitutes the central system of all the processes of an organization. Likewise, from this perspective, it can be said that communication is established as a condition and strategic tool for the processes of the relations of the organization with the environment, and the interaction with the internal personnel.

Currently, it can be seen how firms have realized and believe that communication is able to face globalization, achieving greater organizational development, as well as good communication, a way of acting and think externally, and internally of it. Which generates a change in the behavior of people, right decisions, problem solutions, positive attitudes and collaborative work. That is why those in charge of giving a good internal communication must have in understanding that the process that is implemented, influences the personality and emotions of each person, contributing in turn to job satisfaction, learning, among others.

The interest of the present investigation lies in being able to provide a solution to the problem in progress. For this reason, it is necessary to raise awareness among all the people who are part of an organization about the importance of carrying out this research which leads to satisfactory results. That is why this research aims to demonstrate the impact, the relationship between communication and organizational development. Communication could be understood as a strategic path (Scandelius \& Cohen, 2016; Birim, 2016); whose effects and causes can be reflected commonly in different areas such as labor, leadership, relationships, teamwork, decision making and consequently in the levels of production and development.

Internal communication and organizational development are closely linked, that is why communication is of great importance within human relationships; knowing that it is a process by which one person transmits information to another (Nakamura, Umeki, \& Kato, 2017; Turner, 2017). Communication as a daily and important activity within companies, therefore the success or failure of an organization depends on the people who work in it because it is these that define the work processes and use the resources of it.

The reasons why there are problems in internal communication are the decrease in motivation, the deficiency in internal feedback, the relegation of human talent, the difficulty in a corporate strategy and the lack of knowledge of the organization chart, it is for this should highlight the importance of effective communication between the organization (Nakamura et al., 2017) and all the parties with whom they interact, since the fundamental thing is to analyze and evaluate the attitude or opinion of each of those who are part of a company in order to maintain an affinity and solidarity among them, to promote reciprocal development.

And this is why a poor organizational communication also brings with it consequences such as the decrease in productivity as does understand Castellani, Montresor, Schubert, \& Vezzani (2017), an obstacle in the flow of information, lack of competitiveness, low commitment of workers and a lack of knowledge in the market objectives which if alternative solutions are not generated to this problem, they affect the company not only internally but externally, seriously affecting compliance with business goals and objectives, transcending also the performance of both human talent and the organization.

\section{Justification}

Communication is a tool used by companies to make their values, vision, and objectives known among their collaborators. On this depends, the synergy, the personnel aligned with the corporate strategy and, that the different teams are effective and productive to successfully achieve the proposed objectives. However, caring for communication is vital. Most of the problems in organizations are related to not planning and managing internal communication between the workgroups. Not giving the necessary importance to these situations at the right moment commits the organization, having harmful consequences for its results. So it is necessary to detect communication problems and implement the necessary solutions to prevent or eradicate them completely.

In this study, we approach the internal communication problems in companies, analyze the flagella that directly affect most of the organizations, leading them to not reach the objectives proposed at the productive level. It is desired to propose different contingency or mitigation plans to stop the damage caused by the mismanagement of communication in organizations, under a descriptive analysis. Every day the companies are forced to involve the organizational 
communication because there is a need to be always in constant contact with the members of the company to make the different decisions aimed at increasing the competencies in the market. Corporate strategies are necessary to obtain the results that are expected (Fernandez Hurtado and Martinez Martinez, 2017; Brooks, Chen and Zeng, 2017). This article can highlight the relevant information to systematize the communication problems that affect organizations.

Currently, firms, but especially SMEs, present problems in their external results for the reason of not having communication protocols and monitoring production processes, this generates that business relationships between organizations are affected and automatically distort the company's objectives, mission, and vision. Generally, when workers do not have a solid communication channel, they increase the margin of error in their respective positions in the company and the level of effectiveness is reduced considerably.

A clear example of the above is when customers receive their product in a different way than requested; from the moment the purchase order is entered until the request is sent to the production plant and dispatched, the client's request is altered, which represents not only an inadequate image of the company but a lack of respect for the client and his orders in question.

Therefore, action and prevention measures must be taken that are stipulated, and are part of the company's protocols to increase the effectiveness of productive performance.

\section{Literature Review}

\subsection{The Decrease in Employee Motivation Affects Productivity}

It can be said that companies are a group of people who work every day to achieve a common goal. Internal communication is a key part of organizations to spread their values, vision, mission, and objectives among the human capital that makes up, to deliver a strategic alignment that is efficient and productive enough to achieve the financial goals of companies.

Lo, Lin, \& Hsu (2016); Herzberg (1974) designed an experimental study, in this case, it was specifically designed to study motivation at work, using the critical incident method. Through personal interviews, subjects are asked to remember and describe events related to their work that has made them feel especially good or especially bad; the study also records whether the impact was short or long-term.

Communication allows coherence and integration between actions and objectives; in this sense, the ISO 26000 standard gives particular importance to the human capital that works in the company and is adequate to measure such perception by the impact it promotes in human development. The role played by the employee is fundamental in the company's strategies (Spangenberg, 2016; Castka \& Balzarova, 2008). As companies give importance to generate a corporate culture of permanent communication with their work team, it allows to shape a strategy that motivates its employees constantly, keeping them informed of their achievements and failures, in such a way that the firms make sure that the objectives are understood by all, seeking to collect the opinions of each one, Castka \& Balzarova (2008) Argue that ISO 26000, aware of the influence and importance of human capital within organizations, clearly establishes the impacts it has on people in terms of human rights, labor practices, fair operating practices, environment, consumer issue and the active participation and development of the community, and relate the dimensions of the norm with human development to obtain better processes and results for the company.

It is important that companies support and recognize the achievements of their employees, so that they realize the importance of their work, and motivate them to develop their productive activities with more pleasure and greater efficiency.

In such a way that the employee feels an important part in the company with the role in which works, a greater participation is generated, exchange of ideas and knowledge, allowing to optimize and improve the processes and services provided by the company before these costs are reduced indirectly and profits also increase.

At the birth of a sense of belonging of the worker towards the company, motivation and confidence within the company are increased, making them participants of the projects and decisions that are made, managing to create a commitment on the part of the employee towards the company.

In the workplace, several authors point out the need to establish health and safety programs, training and development; quality motivation programs in employment and better working conditions; of stability in jobs and social assistance to its employees. Programs in which values such as safety, training, team work, worker recognition and benefits prevail, strengthens employees' sense of belonging and trust (MatthewPotoski \& J.Callery, 2018); turning the worker into the best publicity of the company, since they will be the ones that best speak of the business organization.

Achieving a synergy between the corporate strategy of the company and its employees will improve the productive processes, leading the company to be more competitive in the environment, a work team connected with the objectives of 
the company will be more productive. According to the words of MatthewPotoski \& J.Callery (2018) being socially responsible with human capital provides advantages to the company, and certainly, improves your productivity, efficiency, achievement of goals, quality in the activities you carry out and, therefore, improve your financial performance and image of the company.

Theories of traditional motivation focus on specific elements that motivate employees in the pursuit of the performance of the organization. For example, the reasons and the theory of needs of Maslow \& H (1943); Lee \& Raschke (2016) states that employees have five levels of needs: physiological, safety, social, ego and self-actualization.

Applying Maslow theory in a business environment, organizations must be concerned about the welfare of their employees, seeking to improve personal development and self-realization of each individual that is part of the company's environment, with the ability to meet their objectives autonomously in an indicated environment. According to Maslow's needs, they stand out according to the recognition of the person, the particular achievement, and respect for others; they manage to satisfy the needs of each person, managing to develop self-confidence and feel valuable within society, obtaining motivation to aspire to meet new objectives.

According to Herzberg's model, it is a theory of satisfaction, which implicitly assumes the equation "happy employees = high productivity". Although satisfaction can influence performance and vice versa, the translation of performance satisfaction is not automatic. Satisfaction is important from the employee's perspective. But, for there to be motivation in the primary and etymological sense (movement action), there must be an impact on the behavior; the impact on the mood of the employee is not enough (Drieschner, Lammers, \& Van Der Staak, 2004).

Maintain a constant motivation in the company to generate benefits such as increased productivity, the key to performance and profitability of it; the understanding of the ownership of employees, the levers of motivation and the development of the adoption of the adoption of this type of alternative approach, on the conventional empirical analysis (Di Cintio, Ghosh, \& Grassi, 2017). Although motivation is important, it will not be a guarantee for employees who achieve greater productivity, because they may be affected by other external or internal factors.

\subsection{Internal Feedback Generates Information Flow within the Firms}

A process of efficient internal communication requires the creation of a means that allows the correct feedback, since it is necessary to develop any type of action that allows knowing the aspirations and insufficiencies of the workers, knowing that it must go beyond a mailbox of suggestion. The management of the communication, in turn, is responsible for managing, planning and evaluating the information flows that concern both the external and internal client, in relation to the objectives of the company and the sector to which it belongs. Starting from the axiom according to $\mathrm{Lu}, \mathrm{Yuan}, \& \mathrm{Wu}$ (2017) whether it is proposed or not, the organization always communicates, the strategic management of communication becomes an element of primordial competitiveness within organizational contexts. As the author refers Yildirim (2014); Podsakoff, Whiting, Podsakoff, \& Mishra (2011) thus, the contributions of communication to the organization can and need to be measured as other activities carried out by it.

The feedback seeks to be a useful tool for the operation of a company, for this it is important that this is a permanent process and not something sporadic, in which a system should be implemented in the feedback, that is, a rigorous methodology that allows analyzing the information in order to evaluate the objective processes and opinions.

Currently, it is essential to have an internal communication plan in organizations, because an informed worker is more productive, is connected to the company, feels motivated and contributes to the achievement of the proposed objectives, in order to obtain favorable results at the financial level, internal clients are the main ambassadors of companies; it should be noted that the communication that occurs between the leader and his team is the most relevant. The use of digital tools for the transmission of information within organizations, it is becoming timelier every day because it arrives in a timely manner and in real time to workers.

Within the organization, the internet platform proved to be a facilitator in the communication environment, which makes it a valuable tool for internal business management. Therefore, the information flows go in both directions, providing knowledge management to the organization, never before allowed. Interpreting itself as the means of excellence of internal communication, which can help improve and popularize the flow of information of the organization. In addition to this function, even internally, it is related as a tool for the management of information and knowledge of the company.

From the above, this environment provides a database information platform in all areas in an organized and controlled manner. On the other hand employees are connected to a powerful communication medium that connects them to the world. Access to relevant news and events is immediate and more efficient. Participation can be encouraged and facilitate the lives of organizations.

Then, according to Wang, Yuan, \& Wu (2017) communication, therefore, contributes vaguely to the strengthening of identity because it is not based on institutional or conceptual contents. Well-managed internal communication promotes 
cooperation and unity, having excellence in the management of tasks and the recognition of the realities of each individual and their working group. The lack of internal communication strategies causes stagnation in the management, processes, actions and relationships.

The fundamental capital of companies in the 21 st century is being highlighted by their human capital, which is of great importance the care and respect for them, because employees can participate in important decisions of the company, providing different opinions and useful tools for the development of better business management. Success in human management in companies is confirmed by the active recognition and assessment of the human factor.

\subsection{Relegating Human Talent to a Second Level Generates Insufficiency in Business Competitiveness}

Despite having demonstrated the great value that knowledge has, its sharing and its transfer, which are highly beneficial for society, between the company and the workers, there are still attitudes and behaviors that are contrary to such proposals. Sometimes it is due to circumstances that arise in the company that impede or hinder transmission (Antoniades, Calomiris, \& Hitscherich, 2016).

It should be noted, that within business communication it is important that it flows properly. However, there are certain factors that impede, transform the message or hinder the general process of it, and are called barriers, which can range from physical elements to individual attitudes, and a group as an extended absence of employees. The key to identifying these barriers and eliminating their effect is to carefully identify all aspects of them.

(Khedery, 2015) The primary function of human talent is the development of human capital that allows the company to be more competitive every day, operating at maximum efficiency and effectiveness, so that it achieves the success of its strategies.

Based on the above, it can be seen how human talent is a fundamental part of the business, since this is the essence in business management, therefore if it is relegated, it hinders an economic improvement for the company in the productive scenario, that is, if the leaders of the companies do not have a good relationship with their workers, they are not able to stimulate the potential of these, therefore, a lack of competitiveness of the company will be generated. It is necessary to emphasize that the effectiveness of companies is superior when it considers workers as strategic resources, given that in order to be competitive it must strive to be productive, offer quality and excellence in customer service, both internally and externally; value ethics and transparency, as well as social responsibility towards workers and society.

Furthermore, in the 21 st century, the competitive advantage of companies is not measured or measured by their natural, technological, energy and financial resources, but by the level of preparation and empowerment that human talent receives; being this not only the motor but also the only competitive advantage that differentiates it from other companies, making them adapt to the changes that are taking place in the area and the global market.

For this reason, the mission of managers is to establish a strategy to create a correct work environment that ensures that the right person is in the right place within the company (Sirola \& Pitesa, 2018), ensuring that the commitment in the improvement process can satisfy all demands of the company and consumers.

In short, a human talent management system is defined as something very significant, given that it manages and measures the performance of employees through feedback (Cai, Wang, Cui, \& Stanley, 2018), training and support, this allows a clear vision of the competencies that are required to achieve personal and business success.

In addition, adequate personal relationships contribute significantly to the success of knowledge transfer, and create trust and reciprocity among the members of the company, while distancing raises barriers and hinders the transfer. According to Rezvani et al (2016); Gözükara \& Çolakoğlu (2016) the influence of human factors such as interpersonal relationships, motivation, satisfaction, or participation in the company, are key to the success of productivity and the application of knowledge management taking advantage of all human talent.

In conclusion to develop competitiveness strategies and achieve success in a company, it is necessary to establish adequate personal relationships, manage, support and exploit the human potential that the company has, in order to improve performance and quality in each of the productive activities of companies.

This is why the benefits of carrying out a perfect strategy of talent management, helps companies to achieve the identification of the skills and competencies of their workers, which allows to take stock of the skills that exist in companies, despite the changes that are taking place in the global economy; the exit of talent is still one of the concerns of companies, so it is important that retaining a talent for leadership and growth in the market. Therefore, having a strong management culture, also determines the level of organization of the companies, likewise, if the workers tend to be positive about the practices of this management, they come to have more confidence in the future of the companies, which helps ensure a position in the market leadership.

It should be noted that these efforts are an indispensable strategic tool to face the new challenges imposed by the 
competitive environment at the business level. With regard to promoting excellence at the level of individual skills according to the operational activities of companies, ensuring the development and management of the potential of each person.

This refers to management trends, which aim to optimize the management of company personnel, and thus contribute to the development and increase of competitiveness and productivity, these trends try to redeem the human being within an organization, looking for through the identification and management of the potential of the workers, and the goals proposed by the organization can be achieved.

\subsection{Difficulty of Workers to Focus on Corporate Strategy}

The internal communication problems in the company make it difficult to socialize the goals and objectives, which means that the strategies are not precise, encouraging a low commitment on the part of the workers, and so that the internal reputation of the company is affected to the company. As it ratifies by Akin Ateş, van Raaij, \& Wynstra (2015), with its premise: "the structure follows the strategy", in which he attributes to the strategy the previous and independent quality that then conditions the structure, subsequent and dependent that derives from the strategy to be able to fulfill an effective function.

Then, an effective company would be one that manages to add value to each of its interrelationships, and does not lose sight of its contribution to achieve the mission, move towards the vision, meet the objectives and make the strategy a reality (Hetzel, 2016).

What role do workers play in corporate strategy?, it is vital to understand and understand that managers and employees should receive all the information necessary to not distort what they want to achieve, so that the planning in the corporate strategy must be clear to identify their strengths and risks; restructuring and implementing processes that control and reduce the margin of error in companies. Authors as Joniaková \& Blštáková (2015); Ding, Li, \& George (2014) express, human management has evolved from an administrative-operative perspective towards a strategic one concerned with the critical problems of organizations. To do this, it is necessary to know the human talent that is part of the organization, how they capture the information and the position they take in face of the challenges faced by managers every day, their ability to improve productivity, profitability and achieve the company's dynamism. Be competitive, know their potential and review their ability to work as a team, as in many cases, they determine the progress and durability of the organization, it because of a good human talent and at ease with their work makes internal processes efficient and effective.

In this way, an appropriate business management with a permanent link with the productive assets of the company (workers), will obtain an orientation towards innovation, with the environment that surrounds it (e.g., Frank, Cortimiglia, Ribeiro, \& Oliveira, 2016).

Therefore, it is essential to disseminate to all employees about the strategic objectives, the mission, and vision of the company, in order to generate a link with the different areas.

This means that retribution is one of the most powerful means available to companies to send credible messages to their employees about what the company's philosophy, values, objectives, and strategic orientation are; and properly managed, can act as a trigger or catalyst in business change and development projects. When it is instrumentalized on a tangible element, they enjoy an almost immediate visibility, receiving a dose of credibility difficult to achieve with other measures (Price \& Sun, 2017).

This leads to knowing the importance and the need for vigorous work in the corporate culture to achieve flexible organizations, open to change, adaptable: but, above all, committed to strategic processes in competitive markets such as those of today (Gündüz \& Semercišz, 2012).

In this sense, the internal organizational culture of a company makes reference to the customs, norms, practices, projects, beliefs, that is, the modes of proper conduct externalize themselves to the collaborators (Gattringer, Wiener, \& Strehl, 2017). This is what speaks of an organizational culture with an internal and external favorable image.

To finish, the role that workers play in the corporate strategy is very important, since this way, the organization achieves the efficient and effective internal system that it requires for the relationship with the client, supplier and market; in the moment that human talent stops operating properly, the system stops, cuts its process, the most common difficulties and mistakes start within the companies, such as: poorly planned product dispatch to the client, due to lack of communication between the commercial department and logistics coordinator, either because one of the parties is not doing a job with productivity and excellence or because of a poor delivery of information from one to the other, this means extra costs for the company and, in very frequent cases, loss of client, therefore in the company will affect the phrase: "Organizations work with tangible and intangible inputs to produce goods and services in order to obtain profit".

How to focus workers on corporate strategy? For human talent, compensation is important, is what they receive in 
exchange for their services for the company. Over the years, remuneration became not only the payment to the worker but also a strategic management tool to develop and mobilize human capital, orienting the capabilities, attitudes and behavior of employees towards the achievement of business objectives (Katsikea, Theodosiou, \& Morgan, 2015).

Therefore, the objective of companies in terms of employees should be, retain, attract and motivate, these three facets are usually broken down into a list of purposes exposed below (Katsikea et al., 2015).

1. Attract good professionals.

2. Retain them selectively and performance motivation.

3. Improve the work climate and employee satisfaction.

4. Increase performance.

5. Develop talent.

6. To favor the cohesion of the teams and the synergy between units and departments.

7. Promote the commitment and identification of employees with the interests of the company.

8. Communicate objectives and strategy.

9. Disseminate and give credibility to corporate values and philosophy.

Why talent abandons organizations? All causes come together in one sole demotivation. It is enough to perceive, review and analyze what demotivates the members.

The talent usually goes from the companies for the following reasons:

1. The existence of 'tyrant' boss.

2. Lack of autonomy and independence.

3. Unfair internal policies.

4. Problems in recognition.

5. The organization is sinking.

Job satisfaction or job happiness is an important pillar for organizations and to which attention should be paid, even more in the era of changing markets that we live. It is vital, for the survival of an organization, as well as for its permanence and progress, to have people aligned and happy in their work roles (Ward \& King, 2017).

To end a good work not only must have nice motivated, but also satisfied with their expectations within a company, the retribution should not be only economic, there are other factors such as, training, development, participation, reward, importance to your personal life, help in personal and children's education. In order to obtain the key objective: The strategic corporate alignment between managers and employees.

\subsection{The Organization Chart as an Integral Part of the Firm}

In this way, the organization chart is the graphic representation of the structure of an organization, with time it can be restructured, since, it is variable. Respond from human resources to work hand in hand with each area of the company, that is, a structure is ideal for planning and control.

Then, Rydén, Ringberg, \& Wilke (2015) affirm that, an organizational culture is clearly defined and identified in a company when it has: vision and shared values, collective sense of purpose, common mental models, natural leadership and unwritten rules that are lived in everydayness

In this way, in most of the companies nobody is in charge of the processes, they almost do not realize it, does a company have a general manager who takes charge of the dispatch of the orders, of seeing that the products arrive to the clients? Probably not. Who is in charge of developing new products? All departments take part, but nobody is in charge. The companies of today consist of vertical structures. The person who verifies the credit of a client belongs to the credit department, which is part of the financial organization in the organization chart. Those who choose the items in the order work in the warehouse and probably depend on the manufacturing manager, those who are part of a process look inside their own department and up where their superior is, but, nobody looks out, where they are the client. The performance problems of companies lie in the inevitable consequence of the fragmentation of the process (López-Navarro \& Camisón-Zornoza, 2003).

It is important to understand that, in terms of processes, the results allow us to determine the importance of stakeholder participation in defining the objectives of the area, as well as to implement and develop them. These processes of involvement, make communication mechanisms achieve the necessary coordination, which will lead to the success of 
the processes, determined to integrate the work teams, under a precise decision making in pursuit of compliance with financial and productive goals (Abubakar, Elrehail, Alatailat, \& Elçi, 2017).

Given the little communication existing in companies between one department and another, by vertical structures, it is caused that workers do not know who is each of the members of the organization, what are their responsibilities and how they should respond to the tasks of the company, in addition to its subordinates. In this way, Pikhart (2014) affirm that due to the lack of functional delimitation and, therefore, to the lack of conceptual unity in reference to the bodies that are responsible for business communication, it is difficult to establish a historical evolution of their structures. This is why at present the companies do not present economies of scale, that is, the importance of the internal relations of the organization to reduce risks, share responsibilities, vision towards the same objectives. Working aligned alleviates companies from having to hire personnel to reorganize, which due to poor programming requires a process again.

Likewise, the inflexibility, insensibility, lack of directing the client, obsession with the activity rather than with the result. Business people know that factories, service facilities, and sales offices located far from the central office have to be treated as separate organizations, detached from each other and autonomous so that they function efficiently. New technologies free companies from this need to compromise. High bandwidth communication networks allow the central office to have the same information as the branches and see the data they use and vice versa in real time (Persson, 2006).

Connecting the organizational chart of the company with the technological advances and the process diagrams for each department is a good step to better understand the processes that constitute a company, exposing the names that indicate its initial state and its final state.

In conclusion, the new organizational and managerial schemes mirror the way in which the organization thinks and operates, in search of a worker with the capacity to develop the company's objectives; the flexibility before the changes introduced by the organization; a flat, agile and modern structure that generates an atmosphere of work that encourages those who are part of it; a system that is based on the effectiveness of the process where success and risk are shared as mentioned above, creation of internal relationships based on networking; and a participatory work team in the actions of the organization.

\section{Methodology}

In the study of the problems in the internal communication of companies, a descriptive and empirical methodology is established to identify the diagnosis of low business productivity, through the realization 100 samples in count participated workers from different companies; the current state of its communication and thus establish the consequences of a poor organizational communication, based on the variables used, finding the flaws that affect many companies in the Colombian industry and the world, which leads to productive scenarios, based on the information gathered through exhaustive research, its quantitative and qualitative analysis responding to the objectives set out in the research.

The variables used in the research are the following:

The decrease in employee motivation affects the productivity of firms, this variable presents a high degree of importance (Kim \& Patel, 2017), through the events that the employee lives in his workplace, he can feel very good or very bad and this triggers a short or long-term impact.

Internal feedback generates information flow within the company, a variable that indicates that an efficient communication process requires the creation of a medium that enables the correct transmission of information as it is essential to develop any action.

Relegating human talent to second place generates insufficiency in business competitiveness, human talent is paramount in a company and, depending on the importance given to it, and its effectiveness depends since the employee is the essence of management or business management.

The difficulty of the workers to focus on the corporate strategy, since the problems of internal communication in the company, make it difficult to socialize goals and objectives.

The organizational chart as an integral part of the company, since the organizational chart is the graphic representation of the organizational structure, as stated by Da Silva Gonçalves Zangiski, Pinheiro De Lima, \& Gouvea Da Costa (2013) an organizational culture is defined in a company when it has shared vision and values, a collective sense of purpose, common mental models, natural leadership and unwritten rules that are lived in everyday life.

\section{Analysis and Result}

The results obtained are negative with respect to the satisfaction of the personnel of the companies, according to the level of communication that is handled by the company. The results indicate a level of lack in the planning, integration, and importance of human capital that different companies have, especially small and medium-sized companies, where 
management considers these factors of study to be of little importance for the company to maximize its competitiveness, both in the administrative and productive scenario.

Based on the information collected and the variables investigated, it is necessary for companies to introduce in their objectives and goals the importance of employee satisfaction as well as the human capital they have, taking into account that the decrease in employee motivation workers affect productivity, the lack of feedback within the company distorts the flow of information by raising the margin of error; In the same way, it is important that the human resource goes from a second plane to a close-up, where it is understood that this depends on the companies working successfully, in what way? Focusing the workers on the corporate strategy, bringing them closer to the mission, vision, objectives, and composition of the company regarding their organization that can be visualized through the organization chart.

Table 1. Means, standard deviations and correlations

\begin{tabular}{lccccccc}
\hline Variables & Mean & S.D. & 1 & 2 & 3 & 4 & 5 \\
\hline Mission, vision and objectives & 0,36 & 0,482 & 1 & $-0,06$ & $-0,085$ & $-0,039$ & $1,00 * *$ \\
Manage, plan and evaluate & 0,37 & 0,485 & 1 & $-0,10$ & $0,255^{* *}$ & $-0,06$ \\
Human talent & 0,36 & 0,482 & & 1 & 0,09 & $-0,09$ \\
Economic retribution & 0,33 & 0,473 & & & 1 & $-0,04$ \\
Organization chart & 0,36 & 0,482 & & & & 1 \\
\hline$* * p<.05$ & & & & & &
\end{tabular}

All correlations with an absolute value larger than 0.084 are significant at the level $\mathrm{p}<0.05$. Mean values and standard deviations are overall values of non-centered variables. Centering has no impact on standard errors and correlation coefficients. The correlation coefficients are within firm correlations. Given our use of a fixed effects model, we calculated correlations after subtracting for each variable the mean value of the respective firm from the value of the variable.

Table 2. Simple Regression - Economic retribution vs. manage, plan \& evaluate

\begin{tabular}{|c|c|c|c|c|c|}
\hline Model & Sum Squares a & $d f$ & Mean Squares $F$ & $F$ & Sig, \\
\hline Regression & 0,092 & 4 & 0,023 & 0,10 & 0,9826 \\
\hline Residual & 114,54 & 495 & 0,231394 & & \\
\hline Total (Corr.) & 114,632 & 499 & & & \\
\hline
\end{tabular}

The table above (see Table 2) describes the decomposition of the variance of the study data, which were carried out in two components, one component of Regression and another component behind the groups. In addition, it was observed that the significance $F$ in this study was 0.09826 , which corresponds to the quotient between the estimated of Residual and the estimated within the groups analyzed; since the $P$ value of the significance $F$ is greater than or equal to 0.05 , therefore there is no statistically significant difference among the measures of the 5 study variables, this presented by a level of $95 \%$ confidence. 


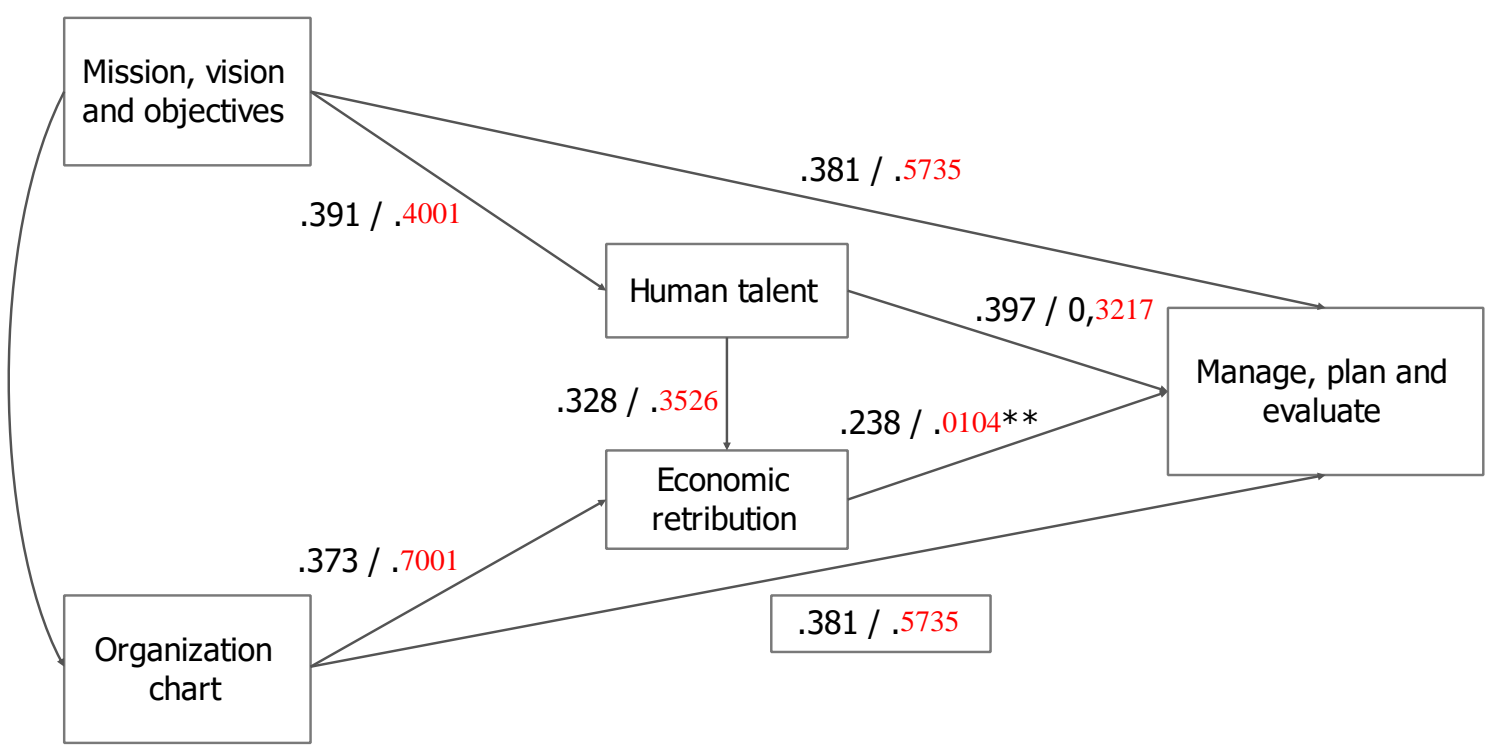

Figure 1. The mediation model of human talent - economic retribution between mission, vision and objective looking for maximize the internal firms' productivity. Unstandardized coefficients on the left and right to be competitive in the market. $* * \mathrm{p}<.05$.

According to Figure 1, it is observed that the ANOVA analysis is $P$ value greater than .05 , which indicates that there is no statistically significant relationship between the analyzed variables such as mission, vision \& objectives in relation to managing, plan and evaluate, although it has a confidence level of $95 \%$ which is usual for the study, in the same way, it was obtained in the other measurements, except the variables economic retribution and manage, plan \& evaluate it does has a relationship statistically significant, given that the ANOVA analysis highlights a $P$ value less than -.05 at a confidence level of $95 \%$, which highlights that a dynamic economy has a growth commensurate with the level of internal administration and strategic planning of companies, promoting high business productivity. It is also noted that the variables studied have a weak correlation coefficient according to the relationship it has.

\section{Conclusion}

To finalize this research, it is worth noting that organizational communication is a key element for the effective development of the productive activities of any company, which is configured in a positive way if the different variables that significantly affect this are identified and analyzed. Aspect, establishing a communicational structure according to the needs and requirements of each organization. That is why communication is of great importance in companies, according to the empirical data thrown by the sample studied; therefore, the correlation provided an analysis in which the entrepreneurs are weak in decision making, as to generate a good working environment, perceived by the correlation analysis of $P$ value, in which it is observed that the variables (economic retribution and manage, plan \& evaluate) have a significant correlation at a statistical level, so, it means that employees require more communicative dynamics in the face of productivity needs, compared to variables that do not have a significant correlation in the study. However, it is necessary to bear in mind that communication helps the company to be more efficient and improve its performance.

As expressed in this research, communication is a component which facilitates business management to be carried out in a successful manner; and it is that the good management of this, helps to maintain the organization, that is to say, that the companies that wish to stand out in the businesses must have a protocol of communication like an exclusive subject, since according to the sample of the study threw data where permeates the need to manage an internal integration of companies, with the purpose of having teamwork, and this will contribute to increasing competitiveness.

Then, with the intention that organizational communication becomes more efficient, companies should seek to implement feedback of the information received, as well as an optimal use of communication resources, both internal and external to the organization, in order to achieve the strategic objectives proposed in the research, and these will be achieved by putting operational lines and the structural environment of the companies into action. 


\section{Acknowledgements}

We would like to thank Dr. GUO Changgang from the Center for Global Studies at Shanghai University for his support to this study. We also would like to thank the General Direction of Research at Universidad Santiago de Cali and to the Department of Operations and Systems at Universidad Autónoma de Occidente for their contribution to the study.

\section{References}

Abubakar, A. M., Elrehail, H., Alatailat, M. A., \& Elçi, A. (2017). Knowledge management, decision-making style and organizational performance. Journal of Innovation \& Knowledge. http://doi.org/10.1016/j.jik.2017.07.003

Akin Ateş, M., van Raaij, E. M., \& Wynstra, F. (2015, May 18). The impact of purchasing strategy-structure (mis)fit on purchasing cost and innovation performance. Journal of Purchasing and Supply Management. Pergamon. http://doi.org/10.1016/j.pursup.2017.05.002

Antoniades, A., Calomiris, C. W., \& Hitscherich, D. M. (2016). No free shop: Why target companies sometimes choose not to buy "go-shop" options. Journal of Economics and Business, 88, 36-64. http://doi.org/10.1016/j.jeconbus.2016.07.003

Birim, B. (2016). Evaluation of Corporate Social Responsibility and Social Media as Key Source of Strategic Communication. Procedia - Social and Behavioral Sciences, 235, 70-75. http://doi.org/10.1016/j.sbspro.2016.11.026

Brooks, C., Chen, Z., \& Zeng, Y. (2017). Institutional Cross-ownership and Corporate Strategy: The Case of Mergers and Acquisitions. Journal of Corporate Finance. http://doi.org/10.1016/j.jcorpfin.2017.11.003

Cai, M., Wang, W., Cui, Y., \& Stanley, H. E. (2018). Multiplex network analysis of employee performance and employee social relationships. Physica A: Statistical Mechanics and Its Applications, 490, 1-12. http://doi.org/10.1016/j.physa.2017.08.008

Casillas, J. C., \& Moreno-Menéndez, A. M. (2017). International business \&amp; family business: Potential dialogue between disciplines. European Journal of Family Business, 1-16. http://doi.org/10.1016/j.ejfb.2017.08.001

Castellani, D., Montresor, S., Schubert, T., \& Vezzani, A. (2017). Multinationality, R\&D and productivity: Evidence from the top R\&D investors worldwide. International Business Review, 26(3), 405-416. http://doi.org/10.1016/j.ibusrev.2016.10.003

Castka, P., \& Balzarova, M. A. (2008). ISO 26000 and supply chains-On the diffusion of the social responsibility standard. International Journal of Production Economics, 111(2), 274-286. http://doi.org/10.1016/j.ijpe.2006.10.017

Da Silva Gonçalves Zangiski, M. A., Pinheiro De Lima, E., \& Gouvea Da Costa, S. E. (2013). Organizational competence building and development: Contributions to operations management. International Journal of Production Economics, 144(1), 76-89. http://doi.org/10.1016/j.ijpe.2013.01.021

Di Cintio, M., Ghosh, S., \& Grassi, E. (2017). Firm growth, R\&D expenditures and exports: An empirical analysis of italian SMEs. Research Policy, 46(4), 836-852. http://doi.org/10.1016/j.respol.2017.02.006

Ding, F., Li, D., \& George, J. F. (2014). Investigating the effects of is strategic leadership on organizational benefits from the perspective of CIO strategic roles. Information and Management, 51(7), 865-879. http://doi.org/10.1016/j.im.2014.08.004

Drieschner, K. H., Lammers, S. M. M., \& Van Der Staak, C. P. F. (2004, January 1). Treatment motivation: An attempt for clarification of an ambiguous concept. Clinical Psychology Review. Pergamon. http://doi.org/10.1016/j.cpr.2003.09.003

Fernandez Hurtado, S. R., \& Martinez Martinez, L. A. (2017). Internationalization of Colombian Firms: Competitive and Productivity as a Problem to Enter the Asian Market. Asian Social Science, 14(1), 183. http://doi.org/10.5539/ass.v14n1p183

Frank, A. G., Cortimiglia, M. N., Ribeiro, J. L. D., \& Oliveira, L. S. de. (2016). The effect of innovation activities on innovation outputs in the Brazilian industry: Market-orientation vs. technology-acquisition strategies. Research Policy, 45(3), 577-592. http://doi.org/10.1016/j.respol.2015.11.011

Gattringer, R., Wiener, M., \& Strehl, F. (2017). The challenge of partner selection in collaborative foresight projects. Technological Forecasting and Social Change, 120, 298-310. http://doi.org/10.1016/j.techfore.2017.01.018

Gözükara, İ., \& Çolakoğlu, N. (2016). The Mediating Effect of Work Family Conflict on the Relationship between Job Autonomy and Job Satisfaction. Procedia - Social and Behavioral Sciences, 229, 253-266. 
http://doi.org/10.1016/j.sbspro.2016.07.136

Gündüz, E., \& Semercišz, F. (2012). The Relation between Competitive Tension and Strategic Innovation. Procedia Social and Behavioral Sciences, 58, 29-39. http://doi.org/10.1016/j.sbspro.2012.09.975

Herzberg, F. (1974). Motivation-hygiene profiles: Pinpointing what ails the organization. Organizational Dynamics, 3(2), 18-29. http://doi.org/10.1016/0090-2616(74)90007-2

Hetzel, R. L. (2016, March 23). A proposal to clarify the objectives and strategy of monetary policy. Journal of Macroeconomics. North-Holland. http://doi.org/10.1016/j.jmacro.2017.03.004

Joniaková, Z., \& Blštáková, J. (2015). Age Management as Contemporary Challenge to Human Resources Management in Slovak Companies. Procedia Economics and Finance, 34, 202-209. http://doi.org/10.1016/S2212-5671(15)01620-2

Katsikea, E., Theodosiou, M., \& Morgan, R. E. (2015). Why people quit: Explaining employee turnover intentions among export sales managers. International Business Review, 24(3), 367-379. http://doi.org/10.1016/j.ibusrev.2014.08.009

Khedery, A. (2015, August 21). Iraq in pieces: Breaking up to stay together. Foreign Affairs. Emerald Group Publishing Limited. http://doi.org/10.1108/17506200710779521

Kim, K. Y., \& Patel, P. C. (2017). Employee ownership and firm performance: A variance decomposition analysis of European firms. Journal of Business Research, 70, 248-254. http://doi.org/10.1016/j.jbusres.2016.08.014

Lee, M. T., \& Raschke, R. L. (2016). Understanding employee motivation and organizational performance: Arguments for a set-theoretic approach. Journal of Innovation \& Knowledge, 1(3), 162-169. http://doi.org/10.1016/j.jik.2016.01.004

Lo, L. Y. S., Lin, S. W., \& Hsu, L. Y. (2016). Motivation for online impulse buying: A two-factor theory perspective. International Journal of Information Management, 36(5), 759-772.

http://doi.org/10.1016/j.ijinfomgt.2016.04.012

López-Navarro, M. Á., \& Camisón-Zornoza, C. (2003, February 1). The effect of group composition and autonomy on the performance of joint ventures (JVs): An analysis based on Spanish export JVs. International Business Review. Pergamon. http://doi.org/10.1016/S0969-5931(02)00086-0

Lu, P., Yuan, S., \& Wu, J. (2017). The interaction effect between intra-organizational and inter-organizational control on the project performance of new product development in open innovation. International Journal of Project Management, 35(8), 1627-1638. http://doi.org/10.1016/j.ijproman.2017.09.009

Maslow, A. H., \& H., A. (1943). A theory of human motivation. Psychological Review, 50(4), 370-396. http://doi.org/10.1037/h0054346

MatthewPotoski, \& J.Callery, P. (2018). Peer communication improves environmental employee engagement programs: Evidence from a quasi-experimental field study. Journal of Cleaner Production, 172, 1486-1500. http://doi.org/10.1016/J.JCLEPRO.2017.10.252

Nakamura, H., Umeki, H., \& Kato, T. (2017). Importance of communication and knowledge of disasters in community-based disaster-prevention meetings. In Safety Science (Vol. 99, pp. 235-243). Elsevier. http://doi.org/10.1016/j.ssci.2016.08.024

Persson, M. (2006). The impact of operational structure, lateral integrative mechanisms and control mechanisms on intra-MNE knowledge transfer. International Business Review, 15(5), 547-569. http://doi.org/10.1016/j.ibusrev.2006.06.001

Pikhart, M. (2014). Implementing New Global Business Trends to Intercultural Business Communication. Procedia Social and Behavioral Sciences, 152, 950-953. http://doi.org/http://dx.doi.org/10.1016/j.sbspro.2014.09.348

Podsakoff, N. P., Whiting, S. W., Podsakoff, P. M., \& Mishra, P. (2011). Effects of organizational citizenship behaviors on selection decisions in employment interviews. Journal of Applied Psychology, 96(2), 310-326. http://doi.org/10.1037/a0020948

Price, J. M., \& Sun, W. (2017). Doing good and doing bad: The impact of corporate social responsibility and irresponsibility on firm performance. Journal of Business Research, 80, 82-97. http://doi.org/10.1016/j.jbusres.2017.07.007

Rezvani, A., Chang, A., Wiewiora, A., Ashkanasy, N. M., Jordan, P. J., \& Zolin, R. (2016). Manager emotional intelligence and project success: The mediating role of job satisfaction and trust. International Journal of Project 
Management, 34(7), 1112-1122. http://doi.org/10.1016/j.ijproman.2016.05.012

Rydén, P., Ringberg, T., \& Wilke, R. (2015). How Managers' Shared Mental Models of Business-Customer Interactions Create Different Sensemaking of Social Media. Journal of Interactive Marketing, 31, 1-16.

http://doi.org/10.1016/j.intmar.2015.03.001

Scandelius, C., \& Cohen, G. (2016). Achieving collaboration with diverse stakeholders-The role of strategic ambiguity in CSR communication. Journal of Business Research, 69(9), 3487-3499. http://doi.org/10.1016/j.jbusres.2016.01.037

Sirola, N., \& Pitesa, M. (2018). The macroeconomic environment and the psychology of work evaluation. Organizational Behavior and Human Decision Processes, 144, 11-24. http://doi.org/10.1016/j.obhdp.2017.09.003

Spangenberg, J. H. (2016). The Corporate Human Development Index CHDI: a tool for corporate social sustainability management and reporting. Journal of Cleaner Production, 134, 414-424. http://doi.org/10.1016/j.jclepro.2015.12.043

Turner, D. C. (2017, August 1). A review of over three decades of research on cat-human and human-cat interactions and relationships. Behavioural Processes. Elsevier. http://doi.org/10.1016/j.beproc.2017.01.008

Wang, P., Yuan, L., \& Wu, J. (2017). The joint effects of social identity and institutional pressures on audit quality: The case of the Chinese Audit Industry. International Business Review, 26(4), 666-682. http://doi.org/10.1016/j.ibusrev.2016.12.007

Ward, S. J., \& King, L. A. (2017). Work and the good life: How work contributes to meaning in life. Research in Organizational Behavior. http://doi.org/10.1016/j.riob.2017.10.001

Yildirim, O. (2014). The Impact of Organizational Communication on Organizational Citizenship Behavior: Research Findings. Procedia - Social and Behavioral Sciences, 150, 1095-1100.

http://doi.org/10.1016/j.sbspro.2014.09.124

\section{Copyrights}

Copyright for this article is retained by the author(s), with first publication rights granted to the journal.

This is an open-access article distributed under the terms and conditions of the Creative Commons Attribution license (http://creativecommons.org/licenses/by/4.0/). 